\title{
Robotic-assisted TKA Reduces Postoperative Alignment Outliers and Improves Gap Balance Compared to Conventional TKA
}

\author{
Eun-Kyoo Song MD, PhD, Jong-Keun Seon MD, PhD, \\ Ji-Hyeon Yim MD, PhD, Nathan A. Netravali PhD, \\ William L. Bargar MD
}

Published online: 6 June 2012

(C) The Association of Bone and Joint Surgeons (B) 2012

\begin{abstract}
Background Several studies have shown mechanical alignment influences the outcome of TKA. Robotic systems have been developed to improve the precision and accuracy of achieving component position and mechanical alignment.

Questions/purposes We determined whether roboticassisted implantation for TKA (1) improved clinical outcome; (2) improved mechanical axis alignment and implant inclination in the coronal and sagittal planes; (3) improved the balance (flexion and extension gaps); and (4) reduced complications, postoperative drainage, and operative time when compared to conventionally implanted TKA over an intermediate-term (minimum 3-year) followup period.
\end{abstract}

One or more of the authors (WLB, JKS, NAN), or a member of their immediate family, have received or may receive payments or benefits, in any 1 year, an amount in excess of $\$ 10,000$, from a commercial entity (Curexo Technology Corp) related to this work. The remaining authors certify that they (EKS, JHY), or a member of their immediate family, have no commercial associations (eg, consultancies, stock ownership, equity interest, patent/licensing arrangements, etc) that might pose a conflict of interest in connection with the submitted article.

All ICMJE Conflict of Interest Forms for authors and Clinical Orthopaedics and Related Research editors and board members are on file with the publication and can be viewed on request.

Each author certifies that his or her institution approved the human protocol for this investigation, that all investigations were conducted in conformity with ethical principles of research, and that informed consent for participation in the study was obtained.

Clinical Orthopaedics and Related Research neither advocates nor endorses the use of any treatment, drug, or device. Readers are encouraged to always seek additional information, including FDA approval status, of any drug or device before clinical use. This study was performed at Chonnam National University Hwasun Hospital (Chonnam, Korea).
Methods We prospectively randomized 100 patients who underwent unilateral TKA into one of two groups: 50 using a robotic-assisted procedure and 50 using conventional manual techniques. Outcome variables considered were postoperative ROM, WOMAC scores, Hospital for Special Surgery (HSS) knee scores, mechanical axis alignment, flexion/extension gap balance, complications, postoperative drainage, and operative time. Minimum followup was 41 months (mean, 65 months; range, 41-81 months).

Results There were no differences in postoperative ROM, WOMAC scores, and HSS knee scores. The roboticassisted group resulted in no mechanical axis outliers $\left(> \pm 3^{\circ}\right.$ from neutral) compared to $24 \%$ in the conventional group. There were fewer robotic-assisted knees

\footnotetext{
E.-K. Song, J.-K. Seon, J.-H. Yim
}

Department of Orthopedic Surgery, Chonnam National

University Hwasun Hospital, Chonnam, Korea

N. A. Netravali

Curexo Technology Corp, Fremont, CA, USA

W. L. Bargar $(\square)$

Department of Orthopaedics, University of California at Davis School of Medicine, Sutter General Hospital, 1020 29th Street, \#450, Sacramento, CA 95816, USA

e-mail:wbargar@jointsurgeons.com 
where the flexion gap exceeded the extension gap by $2 \mathrm{~mm}$. The robotic-assisted procedures took an average of 25 minutes longer than the conventional procedures but had less postoperative blood drainage. There were no differences in complications between groups.

Conclusions Robotic-assisted TKA appears to reduce the number of mechanical axis alignment outliers and improve the ability to achieve flexion-extension gap balance, without any differences in clinical scores or complications when compared to conventional manual techniques.

Level of Evidence Level I, therapeutic study. See Instructions for Authors for a complete description of levels of evidence.

\section{Introduction}

Mechanical alignment and soft tissue balancing have played major roles in the success of TKA, the survival rates of the implants, and patient functionality [22, 44, 54]. Most, but not all, studies have shown that alignment of the mechanical axis in the coronal plane within a range of $3^{\circ}$ varus/valgus is associated with improved long-term function and increased survival rates [13, 23, 35, 41-43]. However, conventional manual implantation of TKA reportedly results in only $28 \%$ to $85 \%$ of cases achieving a mechanical leg alignment deviation within $3^{\circ}$ varus/valgus [29]. Computer navigation has been associated with such alignment in anywhere from $76 \%$ [24] and 100\% of patients [29], but the majority of studies [10-12, 15, 59] have found malalignment of the mechanical axis of greater than $3^{\circ}$ in anywhere from $10 \%$ to $20 \%$ of patients.

Robotic systems have been developed to improve the accuracy of implant selection and placement, alignment, and bone resection during TKA [16, 19, 50]. In these computer-controlled cutting systems, the surgeon provides the surgical exposure and then supervises as the robot precisely machines the bone according to the plan. Several observational studies have shown low rates of alignment error. Two studies showed no cases in which the postoperative alignment error was in excess of $1^{\circ}$ in all three planes $[8,16]$ and one reported all cases had implant placement within $1^{\circ}$ of the preoperative planning in both the frontal and sagittal planes [16]. In comparison to conventional TKA, several studies have reported roboticassisted TKA improved placement of the femoral component in the AP plane when compared to the preoperative plan $[34,51]$ and a more neutral postoperative coronal plane knee alignment [51].

The majority of previous studies $[16,34,51]$ comparing postoperative results have been short term, with a maximum followup period of 3 months. While the 5-year mean followup study by Bellemans et al. [8] found few alignment errors, they did not report function as compared with patients having conventional TKA. Thus, it is unclear whether the low rates of alignment errors from roboticassisted TKA implantation are associated with durable function.

Therefore, we asked whether robotic-assisted implantation for TKA (1) improved clinical outcome as measured by ROM, Hospital for Special Surgery (HSS) knee scores [21], and WOMAC scores; (2) improved the mechanical axis alignment and implant inclination in the coronal and sagittal planes; (3) improved the balance (flexion and extension gaps); and (4) reduced complications, postoperative drainage, and operative time when compared to conventionally implanted TKA over an intermediate-term (minimum 3-year) followup period.

\section{Patients and Methods}

We designed this study as a prospective, randomized trial for which IRB approval was obtained. The population was selected from a group of 176 patients scheduled for unilateral TKA between July 2004 and September 2005. We considered patients with primary osteoarthritis of the knee and a mechanical axis between $20^{\circ}$ and $5^{\circ}$ valgus. We excluded 29 patients who had previous open knee surgery, a BMI of greater than $40 \mathrm{~kg} / \mathrm{m}^{2}$, neurologic defects affecting the lower extremity, or a severe instability that could not be treated by a cruciate-retaining TKA. We performed a power analysis based on the primary outcome variable of percentage of cases within $\pm 3^{\circ}$ of neutral in coronal alignment. The sample size was based on data from a previous study [51] that showed $77 \%$ of conventional cases and $100 \%$ of the robotic group resulted in less than $\pm 3^{\circ}$ of alignment error. Thus, at least 37 patients were required to detect an alignment difference of greater than $3^{\circ}$ (power $\left.=0.8(1-\beta) ; \alpha=0.05\right)$ when incorporating a continuity correction. The goal was to have 100 patients randomly assigned into two groups of 50, one of which received a TKA using the ROBODOC ${ }^{\mathbb{B}}$ System (Curexo Technology Corp, Fremont, CA, USA) for implantation and the other receiving a TKA using a conventional manual technique. One hundred envelopes were sealed with labels denoting either ROBODOC ${ }^{\mathbb{R}}$ or conventional inside. The envelopes were shuffled randomly and arranged for sequential opening with each new patient. We recorded patient enrollment, randomization, and followup; all surgeries took place. The patient cohort for the ROBODOC $^{\circledR}$-assisted group consisted of 46 women and four men with a mean \pm SD age of $66.1 \pm 7.1$ years and a BMI of $26.3 \pm 2.7 \mathrm{~kg} / \mathrm{m}^{2}$. The conventional group consisted of 45 women and five men with an age of $64.8 \pm$ 5.3 years and a BMI of $26.2 \pm 3.9 \mathrm{~kg} / \mathrm{m}^{2}$. Twenty-one 
patients in the $\mathrm{ROBODOC}^{\mathbb{R}}$ group and 26 patients in the conventional group were lost to followup. The minimum followup was 41 months (mean, 65 months; range, 4181 months). We followed the ROBODOC ${ }^{\mathbb{R}}$-assisted group for 65 months postoperatively (range, 58-75 months) and the conventional group for 65 months (range, 4181 months).

One surgeon experienced in both conventional TKA techniques and using the ROBODOC ${ }^{\circledR}$ system for TKA (EKS) conducted all surgeries under general anesthesia. All patients received a posterior cruciate-retaining prosthesis (NexGen $^{\mathrm{TM}}$; Zimmer, Inc, Warsaw, IN, USA). For both groups, the surgeon used the measured resection technique to determine sizing and bone cuts, in which the amount of bone and cartilage removed was intended to be equal to the thickness of the implant, so that the implanted prosthesis resurfaced the knee to its original premorbid state. The bone cuts were considered independent of the soft tissues, and balancing of the soft tissues was completed after the bone cuts were made. The surgical approach for both knees utilized a longitudinal midline incision and a medial parapatellar arthrotomy extending proximally 3 to $4 \mathrm{~cm}$ into the quadriceps tendon and distally to the tibial tubercle. The main goal of both TKA surgeries was to restore the mechanical axis alignment to neutral $\left(0^{\circ}\right)$.

The conventional technique followed the manufacturer's recommended technique using manual instruments. The surgeon prepared the femur using an intramedullary rod set at $6^{\circ}$ of anatomic valgus. The rotation of the femoral component was set at $3^{\circ}$ of external rotation from the posterior condylar axis. The surgeon prepared the tibia using an extramedullary cutting guide and set the posterior slope at $7^{\circ}$. Rotation of the tibial component was aligned with the medial $1 / 3$ of the tibial tubercle.

The surgeon carried out ROBODOC ${ }^{\mathbb{R}}$-assisted TKA in two steps: the first step involved CT-based preoperative planning using ORTHODOC ${ }^{\circledR}$ (Curexo Technology Corp) performed before the day of surgery, and the second step was ROBODOC ${ }^{\mathbb{R}}$-assisted surgery using the ROBODOC ${ }^{\mathbb{R}}$ Surgical Assistant. A helical CT scan was obtained preoperatively and transferred to the ORTHODOC ${ }^{\circledR}$ presurgical planning station. Three-dimensional (3D) surface models of the femur and tibia were created in ORTHODOC ${ }^{\circledR}$, and the femoral and tibial mechanical axes were determined according to the anatomic centers of the hip, knee, and ankle. The surgeon performed ORTHODOC ${ }^{\mathbb{R}}$ preoperative planning for the femoral and tibial components. For each knee, the component size, position, alignment, and rotation were planned according to the following method. The surgeon selected the femoral component and manipulated its size and position in $3 \mathrm{D}$ using the ORTHODOC $^{\mathbb{R}}$ workstation to attempt to restore the original premorbid size and shape of the distal femur, including an assumed cartilage thickness of $3 \mathrm{~mm}[1,4,49]$. The mechanical axis of the patient's femur was determined from the CT scan on ORTHODOC ${ }^{\circledR}$, which allows the surgeon to view the CT images in three orthogonal planes, make angular and distance measurements, and template the implants in 3D. The distal surface of the femoral component was oriented perpendicular to that axis in the coronal plane. If the patient had flexion contractures of greater than $20^{\circ}$, this was taken into account in the preoperative plan and the distal femur was resected an additional $2 \mathrm{~mm}$. The surgeon aligned the rotation of the femoral component with the transepicondylar axis in the axial plane. A tibial component was then selected and its size and position were manipulated to restore the articular surface of the tibia assuming a cartilage thickness of $2 \mathrm{~mm} \mathrm{[1,4,49]}$ on the least worn plateau. The tibial component was aligned perpendicular to a line extending from the center of the tibial plateau to the center of the dome of the talus. The rotation of the tibial component in the axial plane was aligned with the medial $1 / 3$ of the tibial tubercle. The posterior slope of the tibial component was set at $7^{\circ}$. The surgeon then reoriented the bones to make the distal femoral and proximal tibial implant surfaces parallel, using virtual surgery to ensure restoration of the mechanical axis. The final plan was saved to a $\mathrm{CD}$ and loaded onto the ROBODOC $^{\circledR}$ system on the day of surgery.

During surgery, after performing surgical exposure, the knee was flexed to approximately $70^{\circ}$ to $80^{\circ}$ using a special leg holder. The leg was fixed to the ROBODOC ${ }^{\circledR}$ base using two Steinmann and Hoffman fixation systems (Stryker Osteosynthesis, Geneva, Switzerland), one each for the femur and tibia (Fig. 1). Two recovery markers and one bone motion monitor were installed into the femur and tibia. The surgeon then performed surface registration and verification using the ROBODOC $^{\mathbb{R}}$ DigiMatch $^{\mathrm{TM}}$ registration system. Next, under the direct control and supervision of the surgeon, ROBODOC $^{\mathbb{R}}$ milled the femur and tibia according to the plan generated in ORTHODOC ${ }^{\mathbb{R}}$. Care was taken to ensure the soft tissues were protected in the ROBODOC ${ }^{\circledR}$ workspace.

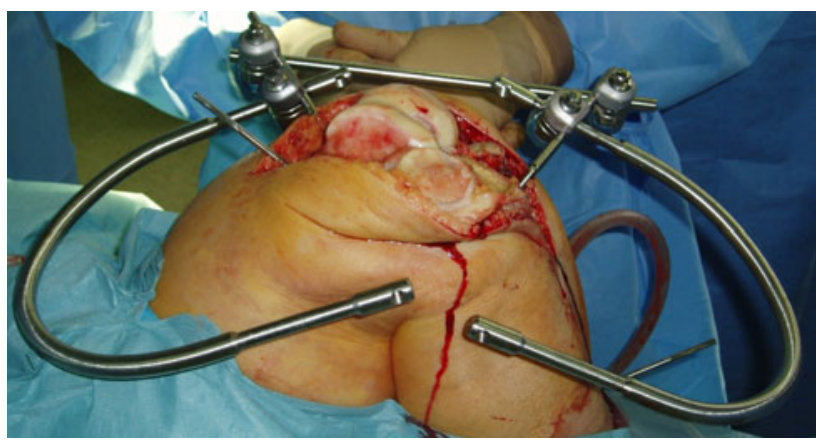

Fig. 1 An example of patient fixation during a ROBODOC ${ }^{\mathbb{R}}$-assisted procedure is shown. 
Once cutting was complete, the ROBODOC ${ }^{\circledR}$ device was removed from the operative field.

The technique for soft tissue balancing for both groups was performed after all bone cuts were made. The technique involved inserting a commercial tensor device (Stryker Howmedica Osteonics Corp, Allendale, NJ, USA) with the knee in extension as described by Winemaker and others [3, $46,47,58]$. The surgeon measured the medial and lateral gaps and made releases as needed to achieve equal medial and lateral gaps to within $\pm 2 \mathrm{~mm}$. The releases were performed in a stepwise manner, releasing only what was required to achieve balance. The order of release for the medial soft tissues was first the deep medial collateral ligament and then in sequential order as necessary: the posterior medial capsule and the superficial medial collateral ligament. No lateral releases were required because no knees in this study had a valgus deformity. The surgeon then measured the extension gap with the tensor and recorded it as the distance from the femur to the tibia in the middle of the gap. The knee was then flexed to $90^{\circ}$, and the flexion gap was measured and compared to the extension gap. The operating surgeon's goal was to create a flexion gap that was greater than the extension gap by $2 \mathrm{~mm}$ [53]. After completing any required soft tissue releases, the medial and lateral gaps were recorded in millimeters at both full extension and $90^{\circ}$ of flexion.

After ligament balancing, the remainder of the procedure was identical for both groups. The surgeon inserted the trial components and verified the ROM and stability. The tibial insert thickness was then chosen. The surgeon recorded his subjective estimate of the adequacy and tension of the PCL as either satisfactory (presence of rollback, no liner liftoff in flexion) or suboptimal (liner liftoff in flexion or absence of rollback). The actual implants were obtained and cemented into place. Suction drains were inserted and the knee closed in a standard fashion.

Postoperatively, both groups received the same treatment. The patients were encouraged to start active and passive knee motion immediately starting the day after surgery if they were able to tolerate the pain. There was no special physiotherapy prescribed or provided to the patients except for ice massages. The patients were also encouraged to walk with partial weightbearing using a crutch or walker as tolerated.

Patients were brought in for followup at 3, 6, and 12 months postoperatively along with annual visits thereafter. At each visit, clinical evaluations were performed and full-length leg radiographs were taken. For the purposes of this study, we analyzed data collected preoperatively and at the latest followup (minimum 36 months after surgery). Two observers (JKS, JHY) with no direct involvement in the surgical procedures independently performed all evaluations. The clinical evaluation included ROM, HSS knee scores [21], and WOMAC scores (for pain and function) [7].
We recorded operative time, complications, and postoperative Hemovac ${ }^{\mathbb{R}}$ (Zimmer Orthopaedic Surgical Products, Dover, OH, USA) drainage amounts to reflect blood loss. Complications were divided into local and systemic and graded as I, II, III, IV, or V using the classification described in Dindo et al. [17].

The same two observers independently performed all radiographic assessments on the preoperative and latest followup radiographs according to The Knee Society Roentgenographic Evaluation System [18], which included measurements of the coronal mechanical axis and sagittal and coronal inclinations of femoral and tibial components. The radiographic measurements were made using a PACS. The interobserver reliability was 0.771 for the measurement of coronal mechanical axis, 0.842 and 0.805 for the coronal inclinations of the femoral and tibial components, respectively, and 0.842 and 0.805 for the sagittal inclinations of the femoral and tibial components, respectively.

We calculated the descriptive statistics, including arithmetic means, SD, and ranges, for all values. To determine differences between the two groups, we performed independent t-tests for postoperative mechanical axis, HSS and WOMAC scores, operative time, and drainage. Chi-square tests were used to determine associations between outliers in radiographic outcomes between the two groups. We performed the analysis using $\mathrm{R}$ software ( $\mathrm{R}$ Version 2.13.1; $\mathrm{R}$ Foundation for Statistical Computing, Vienna, Austria).

\section{Results}

There were no differences between groups regarding the mean postoperative ROM (ROBODOC ${ }^{\circledR}: 128^{\circ}$, conventional: $129^{\circ}$ ), HSS scores $\left(\right.$ ROBODOC $^{\mathbb{R}}: 95.7$, conventional: 94.7), or WOMAC scores (ROBODOC ${ }^{\circledR}: 28.9$, conventional: 30 ) (Table 1).

We found no differences between groups in the means of postoperative mechanical axis alignment $\left(\right.$ ROBODOC $^{\circledR}$ :

Table 1. Clinical results for the ROBODOC ${ }^{\circledR}$-assisted and conventional TKA groups

\begin{tabular}{llcc}
\hline $\begin{array}{l}\text { Clinical } \\
\text { assessment }\end{array}$ & $\begin{array}{l}\text { Time of } \\
\text { assessment }\end{array}$ & ROBODOC $^{\mathbb{R}}$ & Conventional \\
\hline ROM $\left({ }^{\circ}\right)$ & Preoperative & $125 \pm 7.6$ & $123 \pm 12.3$ \\
& Postoperative & $128 \pm 5.1$ & $129 \pm 12.4$ \\
HSS (points) & Preoperative & $70.6 \pm 11.2$ & $63.8 \pm 9.0$ \\
& Latest followup & $95.7 \pm 4.0$ & $94.7 \pm 6.7$ \\
WOMAC (points) & Preoperative & $65.6 \pm 10.2$ & $75.2 \pm 11.1$ \\
& Latest followup & $28.9 \pm 4.4$ & $30 \pm 7.5$ \\
\hline
\end{tabular}

Values are expressed as mean $\pm \mathrm{SD}$; HSS $=$ Hospital for Special Surgery. 
Table 2. Radiographic results for ROBODOC $^{\circledR}$-assisted and conventional TKA groups

\begin{tabular}{lllc}
\hline Radiographic variable & ROBODOC $^{\circledR}$ & Conventional & p value \\
\hline Mechanical axis $\left({ }^{\circ}\right)^{*}$ & & & \\
Preoperative & $6.6 \pm 2.4$ & $10.9 \pm 2.9$ & $<0.001$ \\
Postoperative & $0.5 \pm 1.4$ & $1.2 \pm 2.9$ & 0.06 \\
Coronal inclination $\left(^{\circ}\right)^{*}$ & & & \\
Femoral prosthesis & $89.5 \pm 0.7$ & $88 \pm 1.3$ & $<0.001$ \\
Tibial prosthesis & $90.1 \pm 0.9$ & $90.7 \pm 1.8$ & 0.04 \\
Sagittal inclination $\left(^{\circ}\right)^{*}$ & & & \\
Femoral prosthesis & $1.1 \pm 0.7$ & $1.1 \pm 1.1$ & 0.85 \\
Tibial prosthesis & $85.6 \pm 3.4$ & $86.1 \pm 4.6$ & 0.51 \\
Error $\geq \pm 3^{\circ}$ (number of patients) & & \\
Mechanical axis & 0 & 12 & $<0.001$ \\
Femoral coronal inclination & 0 & 2 & 0.15 \\
Femoral sagittal inclination & 0 & 2 & 0.15 \\
Tibial coronal inclination & 0 & 3 & 0.08 \\
Tibial sagittal inclination & 1 & 3 & 0.31 \\
\hline
\end{tabular}

* Values are expressed as mean \pm SD.

$0.5^{\circ}$, conventional: $1.2^{\circ}$ ), femoral inclination in the coronal $\left(\right.$ ROBODOC $^{\circledR}: 89.5^{\circ}$, conventional: $88.0^{\circ}$ ) and sagittal (ROBODOC ${ }^{\circledR}: 1.1^{\circ}$, conventional: $1.1^{\circ}$ ) planes, and tibial inclination in the coronal (ROBODOC ${ }^{\mathbb{R}}$ : $90.1^{\circ}$, conventional: $90.7^{\circ}$ ) and sagittal $\left(\mathrm{ROBODOC}^{\mathbb{R}}\right.$ : $85.6^{\circ}$, conventional: $86.1^{\circ}$ ) planes (Table 2). When considering outliers (defined as error $\geq \pm 3^{\circ}$ ) for the mechanical axis, femoral coronal and sagittal inclinations, and tibial coronal and sagittal inclinations, the $\mathrm{ROBODOC}^{\circledR}$ group had no outliers for all measurements except for one in tibial sagittal inclination. On the other hand, the conventional group had 12 outliers for mechanical axis, two for femoral coronal inclination, two for femoral sagittal inclination, three for tibial coronal inclination, and three for tibial sagittal inclination.

More $(\mathrm{p}=0.037)$ patients were able to achieve flexionextension gap balance in the ROBODOC ${ }^{\mathbb{R}}$-assisted group (Table 3). The PCL tension measurements demonstrated the ROBODOC $^{\circledR}$ group had a higher $(\mathrm{p}=0.004)$ percentage of patients with satisfactory tension compared to the conventional group (Table 4). All knees in both groups were deemed to be clinically stable using manual and visual assessment by the surgeon with no bony recuts, and no knees required a more constrained implant.

The ROBODOC ${ }^{\circledR}$ group experienced six local and five systemic complications as compared to three local and eight systemic complications for the conventional group (Table 5). There was no difference in the complication rates between the two groups and all were successfully treated using nonsurgical treatment. The ROBODOC $^{\mathbb{R}}$-assisted group experienced less $(\mathrm{p}<0.001)$ postoperative drainage $(613 \pm 318 \mathrm{~mL})$ when compared to the conventional group
Table 3. Intraoperative flexion-extension gaps for the ROBODOC ${ }^{\mathbb{R}}$. assisted and conventional TKA groups

\begin{tabular}{|c|c|c|c|}
\hline \multicolumn{2}{|l|}{ Gap } & ROBODOC $^{\circledR}$ & Conventional \\
\hline \multicolumn{2}{|l|}{ Extension gap $(\mathrm{mm})^{*}$} & $21.4 \pm 1.7$ & $21.8 \pm 1.5$ \\
\hline \multicolumn{2}{|l|}{ Flexion gap $(\mathrm{mm})^{*}$} & $23.5 \pm 1.8$ & $22.9 \pm 2.0$ \\
\hline \multicolumn{2}{|c|}{$\begin{array}{l}\text { Number of cases where flexion } \\
\text { gap - extension gap } \\
\text { was } \geq 2 \pm 2 \mathrm{~mm}\end{array}$} & 3 & 10 \\
\hline \multicolumn{2}{|l|}{$\begin{array}{l}\text { Mean medial-lateral } \\
\text { gap difference }(\mathrm{mm})\end{array}$} & 0.8 & 1.0 \\
\hline \multicolumn{2}{|l|}{$\begin{array}{l}\text { Number of satisfactory cases } \\
\qquad(<2 \mathrm{~mm})\end{array}$} & 46 & 48 \\
\hline \multicolumn{2}{|l|}{$\begin{array}{l}\text { Number of suboptimal } \\
\text { cases }(>2 \mathrm{~mm})\end{array}$} & 4 & 2 \\
\hline \multicolumn{4}{|c|}{ * Values are expressed as mean $\pm \mathrm{SD}$} \\
\hline \multicolumn{4}{|c|}{ Table 4. Intraoperative PCL tension measurements } \\
\hline \multirow[t]{2}{*}{ PCL tension } & \multicolumn{3}{|c|}{ Number of patients } \\
\hline & \multicolumn{2}{|c|}{ ROBODOC $^{\circledR}$} & Conventional \\
\hline Satisfactory & \multicolumn{2}{|c|}{$48(96 \%)$} & $38(76 \%)$ \\
\hline Suboptimal & \multicolumn{2}{|c|}{$2(4 \%)$} & $12(24 \%)$ \\
\hline
\end{tabular}

Table 5. Complications found in patients in the ROBODOC ${ }^{\mathbb{R}}$ assisted and conventional TKA groups

\begin{tabular}{lll}
\hline Type of complication & Complications & Grade* \\
\hline ROBODOC $^{\circledR}$ & & \\
Local $(\mathrm{n}=6)$ & 2 superficial infection & II \\
& 1 seroma at the pin site & II \\
& 2 patellar tendon abrasion & I \\
& 1 skin rash & I \\
& 1 lymphatic edema & I \\
Systemic $(\mathrm{n}=5)$ & 1 crepitus & I \\
& 2 arrhythmia & IVa \\
& 1 plural effusion & IIIa \\
Conventional & & \\
Local $(\mathrm{n}=3)$ & 2 superficial infection & II \\
& 1 incisional skin sloughing & II \\
Systemic $(n=8)$ & 2 GI & II \\
& 1 TIA/CVA & IVa \\
& 3 plural effusion & IIIa \\
& 2 foot numbness & I \\
\hline
\end{tabular}

* Severity classification grade from Dindo et al. [17]; GI = gastrointestinal; TIA $=$ transient ischemic attack; $\mathrm{CVA}=$ cerebrovascular accident.

(933 $\pm 467 \mathrm{~mL}$ ) (Table 6). The mean operative time was 25 minutes longer $(\mathrm{p}<0.001)$ for the ROBODOC ${ }^{\circledR}$-assisted group (99 \pm 11 minutes) compared to the conventional group (74 \pm 10 minutes) (Table 6). 
Table 6. Safety-related results for the ROBODOC ${ }^{\circledR}$-assisted and conventional TKA groups

\begin{tabular}{lccc}
\hline Variable & ROBODOC $^{\circledR}$ & Conventional & $\mathrm{p}$ value \\
\hline Drainage (mL) & $613 \pm 318$ & $933 \pm 467$ & $<0.001$ \\
Operative time (minutes) & $99 \pm 11$ & $74 \pm 10$ & $<0.001$ \\
\hline
\end{tabular}

Values are expressed as mean $\pm \mathrm{SD}$.

\section{Discussion}

The postoperative alignment of the components of a TKA is thought to influence the outcome of patients in terms of functionality and longevity of the implant [23, 44, 54]. Robotic-assisted TKA has been implemented to improve alignment, reduce outliers, and allow more accurate preoperative planning and execution than conventional TKA $[8,16,19,34]$. However, no studies thus far have looked at an intermediate-term (minimum 3-year) comparison of clinical and radiographic results for robotic-assisted TKA and conventional TKA. Thus, we looked at whether robotic-assisted implantation for TKA resulted in (1) improved clinical outcome, (2) improved mechanical axis alignment and implant inclination in coronal and sagittal planes, (3) improved ligament balance (flexion and extension gaps), and (4) a reduced number of complications when compared to conventionally implanted TKA.

A few limitations should be noted. First, there were differences between the groups in the goals for alignment of the femoral component, which could affect limb alignment and ligament balance. A $6^{\circ}$ valgus cut relative to the patient's anatomic femoral canal was the goal in every conventional case without considering any variation in the patient's preoperative femoral anatomy; in the ROBODOC ${ }^{\circledR}$-assisted group, the femoral component was aligned to the patient's individual femoral mechanical axis. A fixed femoral resection angle, however, is reportedly associated with errors in coronal alignment over a population due to individual differences $[5,25]$. Second, the goal for femoral rotation was different in the two groups: in the ROBODOC ${ }^{\circledR}$-assisted group, the femoral component was aligned with the transepicondylar axis, while in the conventional group, it was aligned $3^{\circ}$ externally to the posterior condylar axis. According to the literature $[14,30]$, the best rotation alignment for the femoral component has been parallel to the transepicondylar axis. This axis is identifiable on most CT scans but is difficult for surgeons to identify manually during surgery. Several studies have shown using $3^{\circ}$ of external rotation to the posterior condylar axis may accurately estimate the femoral flexion axis only $65 \%$ to $80 \%$ of the time $[20,30,32]$. Therefore, using a fixed $3^{\circ}$ rotational alignment in the conventional group could have resulted in some of the differences found in this group. Third, we did not measure total blood loss, only the postoperative drainage amount, which does differ. However, drainage reportedly correlates with actual blood loss [28], and since the tourniquet was kept inflated until after wound closure, the postoperative drainage should closely approximate actual blood loss. Fourth, we only measured the flexion and extension gaps once intraoperatively and without patellar relocation. Fifth, the surgeon was not blinded to the procedure when making the intraoperative measurements of PCL tension, which could have resulted in potential bias when making these measurements. Sixth, the two groups had differing lengths of time to latest followup. However, because we were interested in considering most recent outcomes, we decided to use the latest followup available with a minimum of 3 years. Also, this study had insufficient power to detect small differences in complication rates. A final limitation is the inability to assess cost-effectiveness. The cost of the ROBODOC $^{\circledR}$ device varies by country. This study was performed in Korea and the cost structure is not readily generalizable to other countries. As the ROBODOC ${ }^{\circledR}$ system with TKA is not available for sale in the United States at this time, it is difficult to accurately assess its cost.

The clinical results were typical for TKA. The postoperative scores for the ROBODOC ${ }^{\circledR}$ group (HSS, 95.7; WOMAC, 28.9) and the conventional group (HSS, 94.7; WOMAC, 30) were similar to those reported previously for conventional (HSS, 90.6; WOMAC, 32.2), robotic-assisted (HSS, 95.9; WOMAC, 18.5), and navigation-assisted (HSS, 91.6; WOMAC, 31.3) TKAs [48, 51] and suggest both techniques provided adequate clinical outcomes as measured by HSS and WOMAC scores.

Many published studies have concluded an error in coronal mechanical axis alignment of greater than $3^{\circ}$ after TKA results in an increase in patient pain, poorer biomechanics, reduced function, and decreased implant longevity $[6,9,13,22-24,26,27,34,37,40,42,54-56]$. In particular, one prospective randomized study by Choong et al. [13] compared functionality and pain scores over time periods ranging from 6 weeks to 12 months after TKA for 115 patients. They found the key variable influencing clinical outcomes was whether mechanical alignment accuracy within $3^{\circ}$ from neutral was achieved. However, not all studies have agreed. A recent study by Parratte et al. [35] followed a cohort of 398 primary TKAs for 15 years and found a postoperative mechanical axis of $0^{\circ} \pm 3^{\circ} \mathrm{did}$ not result in an improved implant survival rate. Still, the majority of studies, as evidenced above, combined with the clinical experiences of most surgeons, lead the authors to believe these results may not represent the norm. Furthermore, sagittal plane alignment is likely to be important as well. Wasielewski et al. [57] suggested posterior tilting of the tibial component affects the femoral rollback of the tibia, causing PCL tension and affecting the ROM. We 
Table 7. Percentage of mechanical axis outliers reported in the literature for studies using robotic assistance, computer assistance, and conventional methods

\begin{tabular}{llll}
\hline Study & \multicolumn{2}{l}{$\begin{array}{l}\text { Mechanical axis outliers (defined as } \\
\left.\text { malalignment }> \pm 3^{\circ}\right)(\%)\end{array}$} \\
\cline { 2 - 4 } & $\begin{array}{l}\text { Robotic } \\
\text { assistance }\end{array}$ & $\begin{array}{c}\text { Computer } \\
\text { assistance }\end{array}$ & Conventional \\
\hline Song et al. [51] & 0 & & 23 \\
Decking et al. [16] & 0 & & \\
Bellemans et al. [8] & 0 & & 36 \\
Siebert et al. [50] & 2 & 13 & 27 \\
Confalonieri et al. [15] & & 4 & 23 \\
Bathis et al. [6] & & 15 & 33 \\
Chauhan et al. [10] & & 20 & 37 \\
Chin et al. [12] & & 16 & 24 \\
Saragaglia et al. [45] & & 0 & 13 \\
Sparmann et al. [52] & & 0 & 38 \\
Oberst et al. [33] & & & 24 \\
Current study & 0 & & \\
\hline
\end{tabular}

found the ROBODOC ${ }^{\circledR}$ group had fewer outliers (one total) in femoral and tibial sagittal inclination angles when compared to the conventional group, which had five outliers in the sagittal plane. Comparing our results to those reported previously (Table 7), we found robotic assistance for TKA resulted in no outliers in three of the four previous studies and only $2 \%$ outliers in the fourth study. In comparison, computer assistance resulted in anywhere from $0 \%$ to $20 \%$ outliers. All of the studies showed much higher rates of outliers in conventional cases ranging from $13 \%$ to $38 \%$. Thus, our results appear to fit in with those reported previously.

Soft tissue balance is another major factor involved in determining clinical success. Achieving soft tissue balance is usually a subjective surgical impression during TKA, and flexion and extension gaps should be balanced to optimize the space filled by the components and to equally tension the collateral ligaments [3, 54]. Although our results apply to the use of ROBODOC ${ }^{\mathrm{R}}$ by one specific surgeon (EKS), we demonstrated well-balanced rectangular flexion and extension gaps could be achieved in $94 \%$ of the ROBODOC ${ }^{\circledR}$ knees and only $80 \%$ of the conventional knees. These improved balancing results could be attributed to precise femoral component positioning to restore the premorbid joint line, aligning the femoral component rotation to the transepicondylar axis, and the restoration of a normal tibial slope based on the preoperative CT data.

Although the ROBODOC ${ }^{\circledR}$ procedures took an average of 25 minutes longer, the patients experienced no increase in infections or other complications. Several studies reported a correlation between increased operative time and increased risk of infection [31,36], but none have shown that an increase in time of only 20 to 30 minutes is associated with an increased risk of infection. Navigation systems have increased operative time by anywhere from 10 to 20 minutes $[2,38,39]$ and have not increased the patient's risk of infection. Additionally, Peersman et al. [36] determined 127 minutes for a TKA procedure could be interpreted as a critical operative duration in terms of infection risk. Every patient in both groups of our study had operative times of less than 127 minutes. Furthermore, the ROBODOC $^{\circledR}$ group resulted in less postoperative blood drainage than the conventional group, suggesting the increased operative time does not always equate to additional blood loss. We speculate the decreased drainage in our study could be attributed to avoiding opening the intramedullary canal in the ROBODOC ${ }^{\circledR}$ group.

Overall, our results supported previous work $[8,16,34$, 51] demonstrating robotic-assisted TKA can result in fewer outliers in radiographic alignment and an improved ability to achieve flexion-extension gap balance with similar complication rates, reduced postoperative drainage, and increased operative time when compared to conventional TKA at a minimum followup of 3 years.

\section{References}

1. Adam C, Eckstein F, Milz S, Putz R. The distribution of cartilage thickness within the joints of the lower limb of elderly individuals. J Anat. 1998;193:203-213.

2. Anderson KC, Buehler KC, Markel DC. Computer assisted navigation in total knee arthroplasty. $J$ Arthroplasty. 2005;20: 132-138.

3. Asano H, Hoshino A, Wilton TJ. Soft-tissue tension total knee arthroplasty. J Arthroplasty. 2004;19:558-561.

4. Ateshian GA, Soslowsky LJ, Mow CV. Quantitation of articular surface topography and cartilage thickness in knee joints using stereophotogrammetry. J Biomech. 1991;24:761-776.

5. Bardakos N, Cil A, Thompson B, Stocks G. Mechanical axis cannot be restored in total knee arthroplasty with a fixe valgus resection angle. $J$ Arthroplasty. 2007;22:85-89.

6. Bathis H, Perlick L, Tingart M, Perlick C, Luring C, Grifka J. Intraoperative cutting errors in total knee arthroplasty. Arch Orthop Trauma Surg. 2005;125:16-20.

7. Bellamy N, Buchanan WW, Goldsmith $\mathrm{CH}$, Campbell J, Stitt LW. Validation study of WOMAC: a health status instrument for measuring clinical important patient relevant outcomes to antirheumatic drug therapy in patients with osteoarthritis of the hip or knee. J Rheumatol. 1988;15:1833-1840.

8. Bellemans J, Vandenneucker H, Vanlauwe J. Robot-assisted total knee arthroplasty. Clin Orthop Relat Res. 2007;464:111-116.

9. Börner M, Wiesel U, Ditzen W. Clinical experiences with ROBODOC and the Duracon total knee. In: Stiehl JB, Konermann $\mathrm{W}$, Haaker RG, eds. Navigation and Robotics in Total Joint and Spine Surgery. Berlin, Germany: Springer-Verlag; 2004:362-366.

10. Chang CW, Yang CY. Kinematic navigation in total knee replacement-experience from the first 50 cases. J Formos Med Assoc. 2006;105:468-474.

11. Chauhan SK, Scott RG, Breidahl W, Beaver RJ. Computer-assisted knee arthroplasty versus a conventional jig-based technique: a 
randomized, prospective trial. J Bone Joint Surg Br. 2004;86:372377.

12. Chin PL, Yang KY, Yeo SJ, Lo NN. Randomized control trial comparing radiographic total knee arthroplasty implant placement using computer navigation versus conventional technique. J Arthroplasty. 2005;20:618-626.

13. Choong PF, Dowsey MM, Stoney JD. Does accurate anatomical alignment result in better function and quality of life? Comparing conventional and computer-assisted total knee arthroplasty. J Arthroplasty. 2009;24:560-569.

14. Churchill DL, Incavo SJ, Johnson CC, Beynnon BD, The transepicondylar axis approximates the optimal flexion axis of the knee. Clin Orthop Relat Res. 1998;356:111-118.

15. Confalonieri N, Manzotti A, Pullen C, Ragone V. Computerassisted technique versus intramedullary and extramedullary alignment systems in total knee replacement: a radiological comparison. Acta Orthop Belg. 2005;71:703-709.

16. Decking J, Theis C, Achenbach T, Roth E, Nafe B, Eckardt A. Robotic total knee arthroplasty: the accuracy of CT-based component placement. Acta Orthop Scand. 2004;75:573-579.

17. Dindo D, Demartines N, Clavien PA. Classification of surgical complications: a new proposal with evaluation in a cohort of 6336 patients and results of a survey. Ann Surg. 2004;240:205-213.

18. Ewald FC. The Knee Society total knee arthroplasty roentgenographic evaluation and scoring system. Clin Orthop Relat Res. 1989;248:9-12.

19. Fadda M, Marcacci M, Toksvig-Larsen S, Wang T, Meneghello R. Improving accuracy of bone resections using robotics tool holder and a high speed milling cutting tool. J Med Eng Technol. 1998;22:280-284.

20. Fehring TK. Rotational malalignment of the femoral component in total knee arthroplasty. Clin Orthop Relat Res. 2000;380:72-79.

21. Insall JN, Ranawat CS, Aglietti P, Shine J. A comparison of four models of total knee-replacement prostheses. J Bone Joint Surg Am. 1976;58:754-765.

22. Jakopec M, Harris SJ, Rodriguez y Baena F, Gomes P, Cobb J, Davies BL. The first clinical application of a "Hands-On" robotic knee surgery system. Comput Aided Surg. 2001;6:329-339.

23. Jeffery RS, Morris RW, Denham RA. Coronal alignment after total knee replacement. J Bone Joint Surg Br. 1991;73:709-714.

24. Jenny JY, Clemens U, Kohler S, Kiefer H, Kongermann W, Miehlke RK. Consistency of implantation of a total knee arthroplasty with a non-image-based navigation system: a casecontrol study of 235 cases compared with 235 conventionally implanted prostheses. J Arthroplasty. 2005;20:832-839

25. Kharwadkar N, Kent RE, Sharara KH, Naique $\mathrm{S} .5^{\circ}$ to $6^{\circ}$ of distal femoral cut for uncomplicated primary total knee arthroplasty: is it safe? Knee. 2006;13:57-60.

26. Longstaff LM, Sloan K, Stamp N, Scaddan M, Beaver R. Good alignment after total knee arthroplasty leads to faster rehabilitation and better function. J Arthroplasty. 2009;24:570-578.

27. Lotke PA, Ecker ML. Influence of positioning of the prosthesis in total knee replacement. J Bone Joint Surg Am. 1977;59:77-79.

28. Lotke PA, Faralli VJ, Orenstein EM, Ecker ML. Blood loss after total knee replacement: effects of tourniquet release and continuous passive motion. J Bone Joint Surg Am. 1991;73:10371040.

29. Mason JB, Fehring TK, Estok R, Banel D, Fahrbach K. Metaanalysis of alignment outcomes in computer-assisted total knee arthroplasty surgery. J Arthroplasty. 2007;22:1097-1106.

30. Miller MC, Berger RA, Petrella AJ, Karmas A, Rubash HE. Optimizing femoral component rotation in total knee arthroplasty. Clin Orthop Relat Res. 2001;392:38-45.

31. Nagachinta T, Stephens M, Reitz M, Polk BF. Risk factors for surgical-wound infection following cardiac surgery. J Infect Dis. 1987;156:967-973.
32. Nagamine R, Miura H, Bravo CV, Urabe K, Matsuda S, Miyanishi K, Hirata G, Iwamoto Y. Anatomic variations should be considered in total knee arthroplasty. J Orthop Sci. 2000;5:232-237.

33. Oberst M, Berstch C, Wurstlin S, Holz U. CT analysis of leg alignment after conventional vs. navigated knee prosthesis implantation: initial results of a controlled, prospective, and randomized study. Unfallchirurg. 2003;106:941-948.

34. Park SE, Lee CT. Comparison of ROBODOC-assisted and conventional manual implantation of a primary total knee arthroplasty. J Arthroplasty. 2007;22:1054-1059.

35. Parratte S, Pagnano MW, Trousdale RT, Berry DJ. Effect of postoperative mechanical axis alignment on the fifteen-year survival of modern, cemented total knee replacements. J Bone Joint Surg Am. 2010;92:2143-2149.

36. Peersman G, Laskin R, Davis J, Person GE, Richart T. Prolonged operative time correlates with increased infection rate after total knee arthroplasty. HSS J. 2006;2:70-72.

37. Perillo-Marcone A, Barrett DS, Taylor M. The importance of tibial alignment: finite element analysis of tibial malalignment. J Arthroplasty. 2000;15:1020-1027.

38. Perlick L, Bathis H, Tingart M, Perlick C, Grifka J. Navigation in total-knee arthroplasty: CT-based implantation compared with the conventional technique. Acta Orthop Scand. 2004;75:464-470.

39. Plaskos $\mathrm{C}$, Hodgson AJ, Inkpen K, McGraw RW. Bone cutting errors in total knee arthroplasty. J Arthroplasty. 2002;17:698-705.

40. Rand JA, Coventry MB. Ten-year evaluation of geometric total knee arthroplasty. Clin Orthop Relat Res. 1988;232:168-173.

41. Reed SC, Gollish J. The accuracy of femoral intramedullary guides in total knee arthroplasty. J Arthroplasty. 1997;12:677-682.

42. Ritter MA, Davis KE, Meding JB, Pierson JL, Berend ME, Malinzak RA. The effect of alignment and BMI on failure of total knee replacement. J Bone Joint Surg Am. 2011;93:1588-1596.

43. Ritter MA, Faris PM, Keating EM, Meding JB. Postoperative alignment of total knee replacement: its effect on survival. Clin Orthop Relat Res. 1994;299:153-156.

44. Rodriguez JA, Bhende H, Ranawat CT. Total condylar knee replacement: a 20-year follow-up study. Clin Orthop Relat Res. 2001;388:10-17.

45. Saragaglia D, Picard F, Chaussard C, Montbarbon E, Leitner F, Cinquin P. Computer-assisted knee arthroplasty: comparison with a conventional procedure. Results of 50 cases in a prospective, randomized study. Rev Chir Orthop Reparatrice Appar Mot. 2001;87:18-28.

46. Sasanuma H, Sekiya H, Takatoku K, Takada H, Sugimoto N. Evaluation of soft-tissue balance during total knee arthroplasty. J Orthop Surg (Hong Kong). 2010;18:26-30.

47. Sekiya H, Takatoku K, Takada H, Sasanuma H, Sugimoto N. Postoperative lateral ligamentous laxity diminishes with time after TKA in the varus knee. Clin Orthop Relat Res. 2009;467: $1582-1586$.

48. Seon JK, Park SJ, Lee KB, Li G, Kozanek M, Song EK. Functional comparison of total knee arthroplasty performed with and without a navigation system. Int Orthop. 2009;33:987-990.

49. Shepherd DE, Seedhom BB. Thickness of human articular cartilage in joints of the lower limb. Ann Rheum Dis. 1999;58:27-34.

50. Siebert W, Mai S, Kober R, Heeckt PF. Technique and first clinical results of ROBODOC-assisted total knee replacement. Knee. 2002;9:173-180.

51. Song EK, Seon JK, Park SJ, Jung WB, Park HW, Lee GW. Simultaneous bilateral total knee arthroplasty with robotic and conventional techniques: a prospective, randomized study. Knee Surg Sports Traumatol Arthrosc. 2011;19:1069-1076.

52. Sparmann M, Wolke B, Czupalla H, Banzer D, Zink A. Positioning of total knee arthroplasty with and without navigation support: a prospective, randomized study. J Bone Joint Surg Br. 2003;85:830-835. 
53. Sugama R, Kadoya Y, Kobayashi A, Takaoka K. Preparation of the flexion gap affects the extension gap in total knee arthroplasty. $J$ Arthroplasty. 2005;20:602-607.

54. Takahashi T, Wada Y, Yamamoto H. Soft-tissue balancing with pressure distribution during total knee arthroplasty. J Bone Joint Surg Br. 1997;79:235-239.

55. Taylor R, Mittelstadt BD, Paul HA, Hanson W, Kazanzides P, Zuhars JF, Williamson B, Musits B, Glassman E, Bargar WL. An image-directed robotic system for precise orthopaedic surgery. IEEE Trans Robotics Automation. 1994;10:261275.
56. Tew M, Waugh W. Tibiofemoral alignment and the results of knee replacement. J Bone Joint Surg Br. 1985;67:551-556.

57. Wasielewski RG, Galante JO, Leighty RM, Natarajan RN, Rosenberg AG. Wear patterns on retrieved polyethylene tibial inserts and their relationship to technical considerations during total knee arthroplasty. Clin Orthop Relat Res. 1994;299:31-43.

58. Winemaker MJ. Perfect balance in total knee arthroplasty: the elusive compromise. J Arthroplasty. 2002;17:2-10.

59. Zumstein MA, Frauchiger L, Wyss D, Hess R, Ballmer PM. Is restricted femoral navigation sufficient for accuracy of total knee arthroplasty? Clin Orthop Relat Res. 2006;451:80-86. 